\title{
AVALIAÇÃO DE EFICIÊNCIA DO SERVIÇO DE INTERNET MÓVEL NO BRASIL, UTILIZANDO ANÁLISE ENVOLTÓRIA DE DADOS
}

\section{EFFICIENCY ASSESSMENT OF THE MOBILE INTERNET SERVICE IN BRAZIL, USING DATA ENVELOPMENT ANALYSIS}

\section{EVALUACIÓN DE LA EFICIENCIA DEL SERVICIO DE INTERNET MÓVIL EN BRASIL, UTILIZANDO ANÁLISIS ENVOLVENTE DE DATOS}

\section{Lucilene da Silva Leite}

Mestranda em Computação Aplicada Universidade de Brasília, UnB https://orcid.org/0000-0001-6129-3335

E-mail: leite.lucilene@gmail.com

José Carlos Ferrer Simões

Mestrando em da Computação Aplicada Universidade de Brasília, UnB https://orcid.org/0000-0003-2283-1326

E-mail: josecarlos.ferrer@gmail.com

Wallacy Nascimento de Sousa

Mestrando em Computação Aplicada Universidade de Brasília, UnB

E-mail: wallacycapone@gmail.com

João Carlos Félix Souza

Doutor em Economia Universidade de Brasília, UnB

https://orcid.org/0000-0002-9883-8148

E-mail: jocafs@unb.br

Editor Científico: José Edson Lara

Organização Comitê Científico

Double Blind Review pelo SEER/OJS

Recebido em 29.10.2020

Aprovado em 19.02.2021

\section{(c) (1) (8)}

Este trabalho foi licenciado com uma Licença Creative Commons - Atribuição - Não Comercial 3.0 Brasil 


\section{Resumo}

Objetivo do estudo: Avaliar a eficiência do serviço de Internet móvel com o intuito de subsidiar o órgão regulador das Telecomunicações no Brasil, a avaliar os níveis de eficiência das principais operadoras de telefonia móvel do país.

Metodologia/abordagem: A pesquisa empregou a Análise Envoltória de Dados (DEA), com o objetivo de identificar as Unidades de Tomada de Decisão (DMU) e determinar os pontos a serem evoluídos em termos de eficiência. Na segunda etapa, aplicou-se o modelo de regressão Tobit para avaliar as variáveis de impacto na eficiência.

Originalidade/Relevância: A aplicação do DEA mostrou que se trata de ferramenta promissora para apoio ao monitoramento e fiscalização da ANATEL, visto que utiliza diferentes critérios combinados, não somente critérios quantitativos e qualitativos.

Principais resultados: Os resultados do estudo apontaram que o modelo proposto é válido e indicaram que a Operadora 4 cresceu no indicador de eficiência durante os três meses avaliados. As variáveis IDH, bem como o modelo de gestão, representados pelas operadoras são as variáveis de maior impacto para a eficiência. A região Sudeste representada, principalmente, por São Paulo e Rio de Janeiro são responsáveis pelas maiores eficiências relativas.

Contribuições teóricas/metodológicas: É necessário entender quais são os fatores que influenciam direta ou indiretamente a eficiência, de modo que o acompanhamento e fiscalização não sejam somente meras ferramentas de autuação, mas que principalmente gerem resultados significativos na melhoria da prestação de serviços aos consumidores.

Palavras-Chave: Avaliação de Eficiência; Avaliação de Qualidade; Serviço de Internet Móvel; Análise Envoltória de Dados; Tobit.

\section{Abstract}

Objective of the study: To evaluate the efficiency of the mobile Internet service in order to subsidize the Telecommunications regulatory body in Brazil, to evaluate the efficiency levels of the main mobile telephone operators in the country.

Methodology / approach: A research supported by Data Envelopment Analysis (DEA) method, with the objective of identifying as Decision Making Units (DMU) and determining the points to be evolved in terms of efficiency. In the second stage, the Tobit regression model was applied to assess the variables impacting efficiency.

Originality / Relevance: The application of the DEA showed that it is a promising tool to support the monitoring and inspection of ANATEL, since it uses different combined criteria, not only quantitative and qualitative criteria.

Main results: The results of the study pointed out that the proposed model is valid and indicated that Operator 4 growth in the efficiency indicator the three months to take. The HDI 
variables, as well as the management model, represented by the operators are the variables with the greatest impact on efficiency. The Southeast region represented mainly by São Paulo and Rio de Janeiro are responsible for the greatest relative efficiencies.

Theoretical / methodological contributions: It is necessary to understand what are the factors that directly or indirectly influence efficiency, so that monitoring and inspection are not only mere assessment tools, but that mainly generate significant results in improving the provision of services to consumers.

Keywords: Evaluation of Efficiency; Quality Management; Mobile Internet Service; Data Envelopment Analysis; Tobit.

\section{Resumen}

Objetivo del estudio: Evaluar la eficiencia del servicio de Internet móvil para subsidiar al organismo regulador de Telecomunicaciones en Brasil, para evaluar los niveles de eficiencia de los principales operadores de telefonía móvil del país.

Metodología / enfoque: La investigación empleó el Análisis Envolvente de Datos (DEA), con el objetivo de identificar las Unidades de Toma de Decisiones (DMU) y determinar los puntos a evolucionar en términos de eficiencia. En la segunda etapa, se aplicó el modelo de regresión de Tobit para evaluar las variables que impactan en la eficiencia.

Originalidad / Relevancia: La aplicación de la DEA demostró que es una herramienta prometedora para apoyar el seguimiento e inspección de ANATEL, ya que utiliza diferentes criterios combinados, no solo cuantitativos y cualitativos.

Principales resultados: Los resultados del estudio mostraron que el modelo propuesto es válido e indicaron que el Operador 4 creció en el indicador de eficiencia durante los tres meses evaluados. Las variables del IDH, así como el modelo de gestión, representado por los operadores son las variables con mayor impacto en la eficiencia. La región Sudeste, representada principalmente por São Paulo y Río de Janeiro, es la responsable de las mayores eficiencias relativas.

Aportes teóricos / metodológicos: Es necesario comprender cuáles son los factores que directa o indirectamente influyen en la eficiencia, para que el seguimiento y la fiscalización no sean solo meras herramientas de evaluación, sino que principalmente generen resultados significativos en la mejora de la prestación de servicios a los consumidores.

Palabras clave: Evaluación de la eficiencia; Gestión de la calidad; Servicio de Internet móvil; Análisis Envolvente de Datos; Tobit. 


\section{INTRODUÇÃO}

A quebra do monopólio das telecomunicações no fim do século XX aprovado por meio da Emenda Constitucional n. ${ }^{\circ}$ 8, de 15 de agosto de 1995 foi um marco para todo o setor. Segundo a Anatel (2018), a privatização da Embratel - Empresa Brasileira de Telecomunicações - e a entrada de diversos players no mercado de telecomunicações brasileiro foi uma verdadeira revolução nos usos e costumes dos brasileiros, tanto pela universalização do acesso como pela melhoria da qualidade dos serviços prestados aos consumidores.

À vista disso, para a garantia da eficiência dos serviços ofertados pelas empresas de telecomunicações brasileiras, foi criada em 16 de Julho de 1997, por meio da Lei no 9.472, a Agência Nacional de Telecomunicações - Anatel, com o objetivo primordial de regular o mercado de telecomunicações no Brasil, composto por alguns serviços, definidos pela própria Anatel, dentre os quais se destacam: Serviço Móvel Pessoal (SMP), Serviço Telefônico Fixo Comutado (STFC), Serviço de Comunicação Multimídia (SCM) e Serviço de TV por Assinatura (STVA).

Analisando a Resolução no 575, de 28 de outubro de 2011, que aprova o Regulamento de Gestão da Qualidade da Prestação do Serviço Móvel Pessoal - RGQ-SMP e altera o Regulamento do Serviço Móvel Pessoal - SMP, para atingir o seu propósito, a Anatel exige relatórios periódicos com o máximo de informações a respeito do nível dos serviços ofertados e entregues, bem como do nível do atendimento prestado aos consumidores pelas operadoras de serviços de telefonia, de maneira que possa gerir os serviços, avaliar os níveis de serviço, exigir a melhoria no nível de serviço, penalizar pelos maus resultados e, por conseguinte, estimular a melhoria da qualidade nos níveis dos serviços contratados.

Contudo, a forma de gestão atual tem gerado um grande número de multas, mas a satisfação dos usuários e a qualidade do serviço não têm sido impactadas na mesma proporção, e a próprias operadoras reivindicam uma nova forma de medição de qualidade. Mello et al (2001) destacam que os procedimentos em uso são baseados em conceitos essencialmente qualitativos e fortemente dependentes da opinião do avaliador, e quando utilizadas versões quantitativas, ocorre a aplicação de índices brutos que não fornecem subsídios necessários a uma análise mais acurada. 
Ainda de acordo com a Anatel (2018), o sistema atual de avaliação de eficiência dos serviços prestados pelas operadoras no Brasil inclui critérios qualitativos, tais como a Pesquisa Anual de Satisfação dos Usuários, e quantitativos, tais como a medição das Taxas de Download e Upload, as ocorrências de interrupções, a disponibilidade, dentre outros. Esses indicadores são convertidos em parâmetros qualitativos para determinar a eficiência do serviço.

Com o intuito de resolver o problema descrito acima, a pesquisa pretende empregar a Análise Envoltória de Dados (DEA), com o objetivo de identificar as Unidades de Tomada de Decisão (DMU) e determinar os pontos a serem evoluídos em termos de eficiência. A proposta é apresentar um modelo de avaliação de eficiência por meio de indicadores já existentes e utilizados para avaliação do serviço de Internet móvel, especificamente os Serviço Móvel Pessoal (SMP), e verificar a eficiência desses nas 26 Unidades da Federação e Distrito Federal, além de propor indicadores de qualidade que possam aperfeiçoar a fiscalização e monitoramento para a melhoria da oferta dos serviços disponibilizados para os consumidores.

Assim, as seguintes perguntas serão respondidas durante a elaboração do estudo, considerando o período analisado: a) Quais são as operadoras de Internet móvel mais eficientes e menos eficientes? b) Quais são as regiões geográficas e as Unidades de Federação que apresentam maior e menor nível de eficiência dos serviços de Internet móvel no Brasil? c) O modelo de avaliação de eficiência proposto é aplicável e tende a resolver o problema apresentado? E por fim, d) quais as variáveis externas ao cenário que impactam indiretamente na eficiência do serviço das empresas prestadoras de serviços de Internet móvel?

Ao final do estudo deverá ser possível realizar a avaliação da eficiência dos serviços de Internet Móvel prestados pelas quatro operadoras de telefonia, e concluir se a adoção da Análise Envoltória de Dados (DEA), aliada ao Tobit, trouxe ganhos significativos para o processo de gestão de qualidade dos serviços de Internet Móvel ofertados no Brasil.

\section{METODOLOGIA}

A pesquisa contará com o auxílio da ferramenta computacional SIMDEA - Sistema Integrado de Modelagens em Análise Envoltória de Dados, desenvolvida por grupo de pesquisadores da Universidade Federal do Rio Grande do Norte (UFRN). E o modelo de regressão Tobit para a realização de procedimento de inferência necessário à avaliação do impacto das variáveis exógenas na eficiência. 
As variáveis selecionadas dos 14 Indicadores de Qualidade e que foram consideradas mais relevantes para entradas (inputs) são os indicadores de Disponibilidade; Taxas de Download, Taxas de Upload e para as saídas (outputs) as quantidades de antenas instaladas obtidas do Mapa de Distribuição de Estações de Rádio Base (ERBs) e os índices de satisfação dos consumidores obtidos por meio da Pesquisa Anual de Satisfação.

As DMUs - Unidades de Tomada de Decisão - serão uma combinação das Operadoras analisadas, assim denominadas Operadora 1, Operadora 2, Operadora 3 e Operadora 4, sendo as quatro principais operadoras de telefonia móvel do país; do período analisado, compreendendo os meses de Outubro, Novembro e Dezembro de 2018; e das 27 Unidades da Federação (UF) do Brasil, resultando em um número total de 324 DMUs (27 UF x 4 Operadoras x 3 meses). Como exemplo, é possível citar a DMU Operadoral_Out_MA, que compreende os dados da Operadora 1 no mês de Outubro de 2018 para o estado do Maranhão.

Para o cálculo da regressão, serão utilizados os resultados das eficiências como variável dependente e como variáveis independentes as próprias variáveis que compuseram a DMU: Região Norte, Região Nordeste, Região Sudeste, Região Sul e Região Centro Oeste; os meses de Outubro, Novembro e Dezembro e as Operadoras 1, 2, 3 e 4. Além disso, utilizaremos as variáveis independentes: Índice de Desenvolvimento Humano (IDH), Densidade demográfica (dados do IBGE de Julho de 2018), e Produto Interno Bruto (PIB), com dados do IBGE de 2018. Essas variáveis foram coletadas por UF e escolhidas por serem informações que podem afetar indiretamente a qualidade dos serviços ofertados.

O modelo de avaliação de eficiência será apresentado em três etapas, compreendendo: 1. Seleção, qualificação e organização dos dados obtidos da Anatel; 2. Geração dos escores de eficiência e análise das informações geradas, contendo os resultados das operadoras mais eficientes no trimestre, em cada um dos meses, e em cada uma das Regiões e UF; 3. Cálculo da regressão, considerando fatores indiretos - variáveis independentes e exógenas, que podem influenciar na eficiência.

\section{REFERENCIAL TEÓRICO}

\subsection{Processo de Avaliação de Eficiência do Serviço de Internet Móvel no Brasil}

Segundo a Anatel (2018), o acompanhamento dos indicadores regulamentados vigentes para a qualidade da telefonia móvel (Serviço Móvel Pessoal - SMP) foi aprovado por meio da Resolução $n^{\circ} 575 / 2011$. Nesse instrumento normativo estão previstas as obrigações exigíveis 
das prestadoras de telefonia móvel no que tange à qualidade. Esse controle é aplicável, atualmente, às prestadoras com mais de $5 \%$ de participação em algum dos mercados nacionais de varejo em que atua, e está baseado no acompanhamento do conjunto de 14 (quatorze) indicadores operacionais medidos mensalmente, para os quais há metas estabelecidas com abrangência de medição por DDD (código constituído por 2 dígitos que identificam as principais cidades do país) ou por Unidade de Federação.

Tais indicadores foram escolhidos por demonstrarem o desempenho das prestadoras em quatro aspectos: reação do usuário, rede, conexão de dados e atendimento. E também por serem capazes de demonstrar congestionamentos e quedas na rede de acesso do município, possuírem disponibilidade técnica de cálculo na granularidade de município, serem calculados pela fiscalização da Anatel de forma certificada e padronizada, serem indicadores relacionados com as principais reclamações recebidas em relação ao funcionamento do serviço e serem indicadores usados regularmente pela indústria de telecomunicações no Brasil e em todo o mundo como métricas mais comuns de desempenho de serviço de rede de serviço móvel.

Segue abaixo gráfico extraído do Relatório de Qualidade de Telefonia Móvel da Anatel (2018) contendo o cumprimento das metas por grupo de indicador entre Jan-Dez de 2018:

\section{Figura 1}

Cumprimento de Metas por Grupo de Indicador (jan-dez/2018)

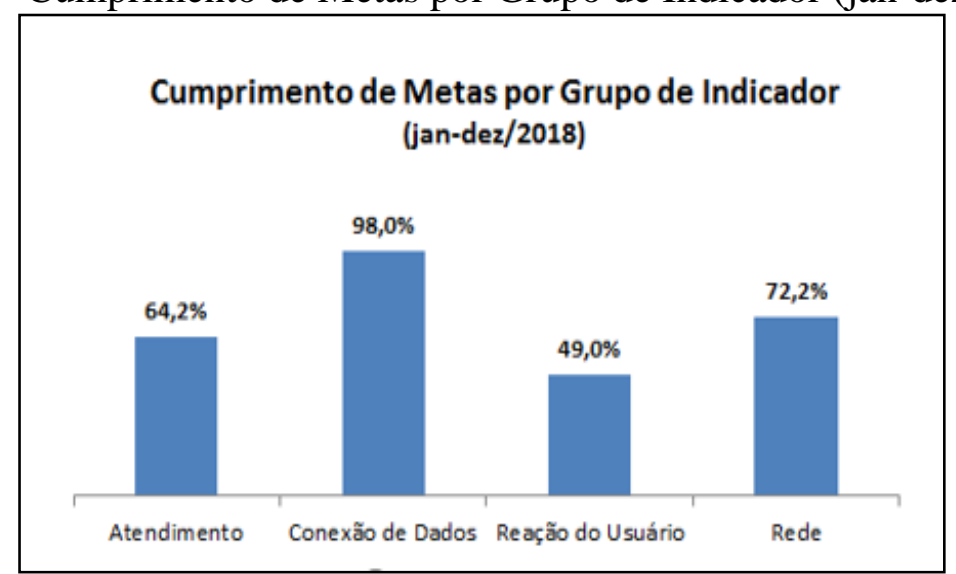

Fonte: ANATEL (2019)

Em razão do exposto e objetivando apresentar uma visão consolidada da qualidade do serviço, a Anatel utiliza como métrica de avaliação da qualidade, o percentual de cumprimento das metas dos indicadores, equivalente ao Índice Geral de Qualidade Operacional - IGQO, previsto para o STFC (Serviço Telefônico Fixo Comutado), que 
consiste na divisão entre a quantidade de indicadores que atingiram as metas regulamentares pelo total de indicadores válidos acompanhados no período, sem prejuízo da publicação do IDQ (Índice de Desempenho na Qualidade). Outra razão para a escolha dessa métrica (IGQO) para avaliação dos indicadores se deve em razão desse índice permitir a comparação do serviço SMP com os demais serviços acompanhados pela Anatel. (ANATEL, 2019).

O gráfico abaixo (Figura 2), retirado do relatório da Anatel (2018) já citado acima, demonstra a evolução histórica de resultados anuais, avaliando-se o percentual de cumprimento de metas, considerando-se todas as prestadoras e medições realizadas em cada ano:

Figura 2

Evolução Histórica do Cumprimento de Metas do SMP

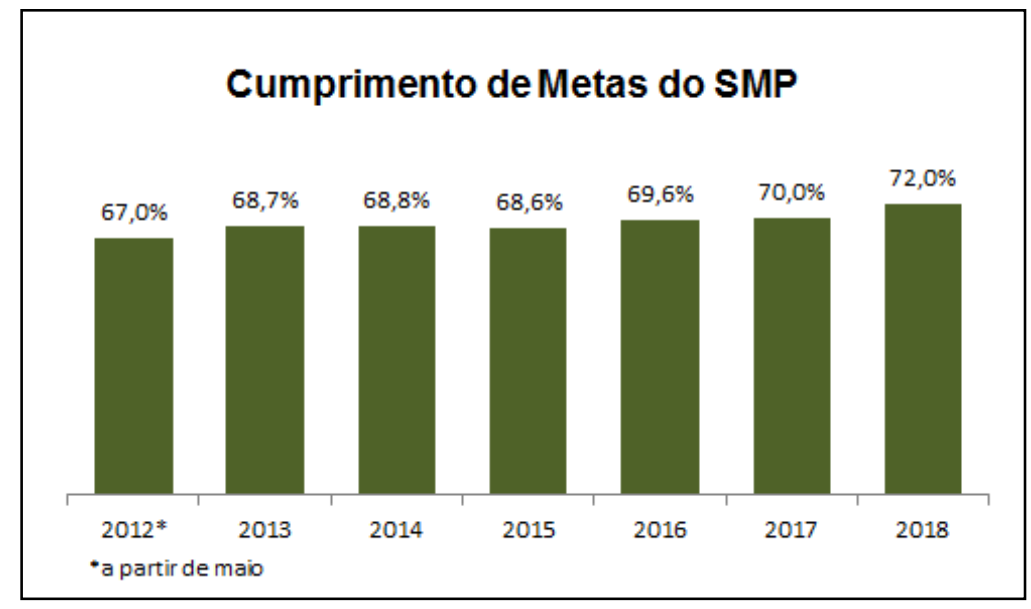

Fonte: ANATEL (2019)

A busca da eficiência e qualidade do serviço de telefonia móvel tem exigido da Anatel a necessidade em diagnosticar, desenvolver técnicas e métodos para avaliar e medir o desempenho do serviço oferecido. Estas técnicas servem como subsídio de apoio às tomadas de decisões com a proposta de alocar os recursos de maneira adequada nos ajustes que serão necessários para melhorar a eficiência dos serviços prestados pelas operadoras. Pensando nisso, foi publicada a Resolução $\mathrm{n}^{\mathrm{o}}$ 717, de 23 de dezembro de 2019, que aprova o Regulamento de Qualidade dos Serviços de Telecomunicações, substituindo assim a Resolução nº 575/2011.

De acordo com a própria Anatel (2019), há uma mudança de foco para o acompanhamento de alguns indicadores estratégicos a fim de atingir o padrão de qualidade desejável e que seja considerado, entre outros, aspectos como a percepção dos usuários e a 
competição. Há também preocupação em prover informações críveis ao consumidor para auxiliá-lo em suas decisões de consumo. Além disso, é importante que haja redução do custo operacional, tanto da agência reguladora quanto das empresas, reestabelecendo o foco da gestão da qualidade na resolução dos problemas identificados em detrimento de atividades que dão pouco retorno para a melhoria da qualidade. Resumindo, essa nova resolução pretende resolver os problemas gerados pela regulamentação anterior no que pese aos custos operacionais e de gestão decorrentes em grande parte da ocorrência de sanções e penalidades imputadas para as operadoras para aqueles indicadores pouco ou nada relevantes para a melhoria da qualidade.

\subsection{Análise Envoltória de Dados (Data Envelopment Analysis) - DEA}

A Análise Envoltória de Dados (DEA) é uma ferramenta matemática baseada em programação linear desenvolvida por Charnes, Cooper e Rhodes em 1978 (Lins et al., 2007). Essa técnica tem como objetivo identificar as Unidades de Tomada de Decisão (DMU) e determinar os pontos a serem evoluídos em termos de eficiência - índice de eficiência - para os indicadores citados anteriormente: Disponibilidade; Taxas de Download; Taxas de Upload; Mapa de Distribuição de Estações Rádio Base e Relatório de Satisfação dos Consumidores.

Conforme descrito por Barbosa e Wilhelm (2009), a metodologia DEA tem por objetivo comparar certos números de Unidades de Tomada de Decisão (DMU) que realizam tarefas similares e somente se diferenciam nas quantidades de insumos que consomem e nas quantidades de produtos que produzem. O objetivo do modelo DEA é identificar as DMUs que, de alguma maneira, não estão sendo eficientes e determinar os pontos que causam a ineficiência.

Nas palavras de Sales (2011), o DEA pode ser visto como um método não paramétrico de definição de uma fronteira de eficiência, de modo que se pode estimar a eficiência relativa de cada unidade, e determinar os benchmarks para unidades ineficientes. Assim, o DEA fornece uma medida de eficiência que determina a proporção em que devem ser reduzidos os insumos (inputs), ou aumentado os produtos (outputs), para se alcançar a fronteira da eficiência.

De acordo com Peña (2008), a combinação ótima dos insumos e métodos necessários (inputs) no processo produtivo de modo que gerem o máximo de produto (output) é o que se conceitua como eficiência. Isto significa que a eficiência é a capacidade de fazer certo as 
coisas, de minimizar a relação insumos - produtos. Visa assegurar a otimização da utilização dos recursos e, portanto, relaciona-se com os meios e não com os fins.

Peña (2008) ainda explica que a eficiência pode ser de dois tipos: eficiência técnica e eficiência econômica. Um método de produção é eficiente do ponto de vista tecnológico, quando se emprega o menor nível de insumos possível para produzir um nível dado de produção, ou quando se obtém o maior nível de produção possível com um dado nível de insumo. Um método produtivo é mais eficiente do ponto de vista econômico que outro, quando o primeiro consegue uma quantidade de produto igual ao do segundo com menor custo, ou quando com o mesmo custo se obtém um nível de produção maior.

Em contraste com outros métodos de modelagem paramétricos como, por exemplo, as técnicas baseadas em regressão linear, cujo objetivo é gerar uma curva que minimize a soma dos erros quadráticos ou absolutos de uma série histórica qualquer, o DEA busca otimizar cada unidade tomadora de decisão de forma individual, objetivando aproximá-las da fronteira de eficiência, a qual é determinada pelas unidades Pareto eficientes, onde não é possível melhorar uma característica sem necessariamente piorar as demais (Soares de Mello et al., 2001).

São várias as formulações dos modelos de DEA encontrados na literatura, conforme afirma Bandin (1995), porém são dois os modelos básicos mais utilizados nas aplicações. O primeiro, denominado Modelo CCR, foi elaborado por Charnes, Cooper e Rhodes em 1978 e permite analisar os retornos constantes de escala (CRS) a partir de uma avaliação da eficiência global entre todas as companhias que fazem parte desse grupo e revela as fontes de ineficiência presentes nele (Kassai, 2002; Lins et al., 2007). O segundo, nomeado de Modelo BCC, foi aprimorado por Banker, Charnes e Cooper em 1984, inclui os retornos das variáveis de escala, estima a eficiência técnica pura em relação a uma escala de operações, identifica ganhos de escala crescente, decrescente e constante (VRS), além disso, também difere as ineficiências técnica e de escala (Kassai, 2002; Lins et al., 2007).

Cabe esclarecer que não foram encontradas pesquisas anteriores com proposta de utilização do DEA para avaliação de índices de eficiência de serviços de telefonia móvel, porém há trabalhos que empregaram tal metodologia para medição de eficiência em outras áreas, tais como distribuidoras de energia elétrica, empresas de aviação, universidades, serviços do setor público e privado, etc, que serviram de modelo na construção deste artigo. 
Como exemplo, Bittencourt Neto et al. (2018) propõem a aplicação do DEA para mensurar a eficiência na arrecadação de tributos dos contribuintes do ICMS, utilizando como entrada (input) as variáveis componentes da função de cálculo do imposto encontradas nos valores registrados nas Notas Fiscais Eletrônicas (compras e vendas) e no faturamento obtido com as vendas realizadas com Cartão (crédito e débito). Nessa pesquisa, os autores optaram pelo Modelo CRS (Constant Returns to Scale ou CCR) com orientação ao output.

Pensando na combinação do DEA com um método de cálculo de regressão, Sousa e Souza (2014), usaram o método dos mínimos quadrados ordinários (MQOs) e regressão quantílica para investigar como as variáveis exógenas influenciam os resultados computados de eficiência. A técnica de regressão quantílica mostrou que os escores de eficiência são positivamente relacionados com o tamanho da agência e a renda per capita dos clientes.

Contudo, o que se assemelha mais com a proposta deste artigo, pela utilização do DEA em conjunto com modelo de regressão Tobit, é o artigo de Moreira et al. (2011), quando os autores utilizaram Análise Envoltória de Dados (DEA) e modelo de regressão censurada (Tobit) em dados de painel. Da mesma forma Wilhelm e Barbosa (2009) também usaram os dois métodos para analisar a influência dos Fatores Sociais e Econômicos no desempenho das Escolas Públicas. Os autores, através dos modelos DEA: CCR, BCC e Avaliação Cruzada, determinaram os índices de desempenho (eficiência) das escolas, utilizando variáveis de recursos financeiros e estrutura como input e resultado escolar como output. Posteriormente, usaram a Regressão Tobit para captar a influência e o impacto de fatores sociais e econômicos, das famílias dos alunos, no desempenho destas escolas.

Além desses, Lins et al. (2007) demonstra como a modelagem por Análise Envoltória de Dados (DEA) permite aferir o desempenho dos hospitais e subsidiar a avaliação da implantação da Política de Reestruturação dos Hospitais de Ensino. A pesquisa é desenvolvida com os 31 hospitais gerais pertencentes as universidades federais brasileiras. Consideram-se indicadores de assistência, ensino e pesquisa. A modelagem também permite indicar as mudanças necessárias para as unidades ineficientes (alterações nos inputs e/ou outputs) e gerar recomendações sobre a distribuição dos recursos públicos baseada em qualidade/eficiência.

Ainda em relação aos diferentes modelos DEA, Sales (2011) descreve sobre os dois modelos mais utilizados na Análise Envoltória de Dados de forma a utilizar dois tipos diferentes de eficiência. 
"A primeira é denominada CRS (Constant Returns to Scale), a qual mede a eficiência produtiva e leva em consideração que todas as unidades operam com retornos constantes de escala, isto é, o aumento no valor de um determinado insumo tem um impacto linearmente proporcional na quantidade que é produzida. A outra é conhecida como VRS (Variable Returns to Scale), a qual mede a eficiência técnica considerando retornos variáveis de escala, ou seja, o aumento de uma unidade no valor de um insumo pode gerar um efeito crescente ou decrescente na curva de produção." (SALES, 2011)

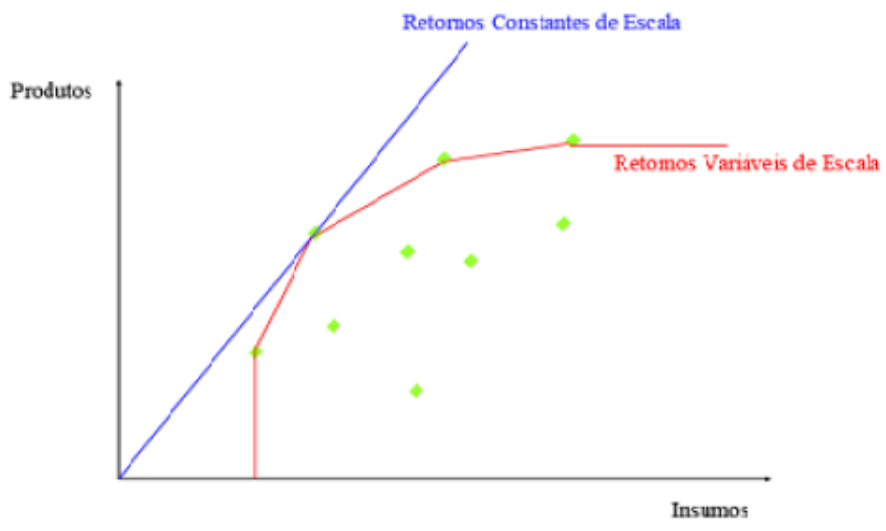

Fonte: Adaptado SOARES de Mello et at (2005)

Figura 3- Retornos constantes e variáveis de escala

De forma a aplicar o Modelo DEA, foi utilizado a metodologia, com base no trabalho de Souza et al. (2014), na qual para cada DMU, a tecnologia transforma insumos não negativos $x^{k}=\left(x_{k 1}, \ldots, x_{k N}\right) \in \mathfrak{R}_{+}^{N}$ em produtos não negativos $y^{k}=\left(y_{k 1}, \ldots, y_{k M}\right) \in \mathfrak{R}_{+}^{N}$. Quando a medida de eficiência técnica é orientada para insumo, a tecnologia é representada pelo conjunto de possibilidades de produção $T=\{(x, y): x$ pode produzir $y\}$, que inclui todos os vetores de insumo e produtos factíveis. A correspondência de insumos para a tecnologia de referência DEA, caracterizada por retornos constantes de escala $(C)$ e pela existência de livre descarte de insumos (S), define a tecnologia linear, construída a partir das combinações observadas de insumos e produtos em (1).

A matriz $M$ com dimensão $k \times m$ possui $m$ produtos observados em $k$ DMUs; $N$ representa a matriz $k x n$ com $n$ insumos; e $z$ é o vetor $1 x k$ dos parâmetros. Para cada atividade, a eficiência técnica nos insumos, $F i$, pode ser definida conforme (2).

$$
L(y \mid C, S)=\left\{x: y \leq z M, z N \leq x, z \in \mathfrak{R}_{+}^{K}, y \in \mathfrak{R}_{+}^{N}\right\}
$$




$$
F_{i}\left(y^{k}, x^{k} \mid C, S\right)=\min \left\{\theta: \theta x \in L\left(y^{k} \mid C, S\right)\right\}
$$

Observar que a medida de eficiência radial varia entre 0 e 1. Usando-se a tecnologia especificada em (1), a eficiência técnica (orientada para o insumo) para cada DMU $k$ pode ser calculada como a solução do seguinte problema de programação linear (3):

$$
\begin{aligned}
& \qquad \theta_{k}=\min (\theta) \\
& \text { Sujeito a: } \\
& \theta x_{k m} \geq \sum_{j=1}^{K} z_{k j} x_{j m} \quad n=1, \ldots, N \\
& y_{k m m} \leq \sum_{j=1}^{K} z_{k j} y_{j m m} \quad m=1, \ldots, M \\
& \theta, z_{k j} \geq 0 \quad j=1, \ldots, K
\end{aligned}
$$

Segundo Sousa e Souza (2014), essa versão de metodologia de DEA implica fortes restrições sobre a produção, sendo conhecida como modelo CCR ou CRS. Esta suposição pode ser facilmente relaxada, modificando-se as restrições sobre o vetor intensidade $z$. Inclusive Färe, Grosskopf e Lovel (1994) adicionaram ao problema (3) a restrição (4).

$$
\sum_{j=1}^{K} z_{k j} \leq 1 \quad j=1, \cdots, K ; \quad k=1, \ldots, K
$$

No modelo de eficiência DEA-BBC, os índices de eficiência são obtidos mediante a imposição de igualdade na restrição (4). Pode-se verificar durante a pesquisa que os modelos de análise de eficiência com o DEA produzem resultados situados entre $0 \%$ a $100 \%$ ou 0 a 1. Sendo assim, a aplicação da regressão linear que, utiliza a aplicação de modelos de mínimos quadrados ordinários, pode ser problemática nestas condições, devendo-se adotar a regressão Tobit (Marinho, 2003).

\subsection{Regressão Tobit}

A Regressão Tobit foi desenvolvida por James Tobim em 1958 e indica a influência dos fatores nos índices de eficiência (AMEMIYA, 1984). Essa técnica de regressão é a mais comumente encontrada em análises envolvendo a segunda etapa do DEA, quando se trata de 
analisar a relação entre os coeficientes de eficiência e as variáveis explanatórias (HOFF, 2006).

Ainda de acordo com Thanassoulis (1993) a técnica DEA e a análise de regressão são métodos alternativos que podem ser usados em conjunto para comparar a eficiência em processos e atividades nas organizações. De acordo com GUJARATI (2000) citado por Moreira et al (2011) para estimar a regressão, em que a amostra é censurada, não se pode utilizar o Método dos Mínimos Quadrados Ordinários, uma vez que os parâmetros extraídos seriam tendenciosos e inconsistentes, pela ausência de informações de algumas observações, ou pela censura dos dados observados.

A base do modelo Tobit é similar à regressão linear, porém assume uma distribuição normal censurada e, torna-se um eficiente método para estimar a relação entre uma variável dependente censurada e outras variáveis independentes (AMEMIYA, 1984; RIOS, 2005). Por oportuno, segundo Greene (1997), uma distribuição truncada é um subconjunto de uma distribuição não truncada, com dados acima ou abaixo de um determinado valor.

Esse modelo de regressão foi escolhido dentre os modelos existentes, visto que os escores fornecidos pelo DEA possuem valores que variam de 0 a 1 , portanto, tem-se uma censura à direita na variável de interesse, o que requer um modelo que seja capaz de lidar com essa lacuna (RIOS, 2005). No modelo em questão os resultados da eficiência gerados na aplicação do DEA serão utilizados como variável dependente. As variáveis independentes serão o Índice de Desenvolvimento Humano (IDH), a Densidade demográfica com dados referentes a julho de 2018, e o PIB-UF, todos os dados extraídos do IBGE/2018.

Outro ponto considerado é que na análise de regressão, a variável dependente pode ser influenciada por variáveis quantitativas e qualitativas. De acordo com Missio e Jacobi (2007), as variáveis quantitativas são facilmente mensuradas em alguma escala, como exemplo as variáveis PIB-UF, IDH-UF e Densidade Demográfica citadas acima, o que não ocorre com as variáveis qualitativas, uma vez que essas indicam a presença ou a ausência de uma qualidade ou atributo. Dessa forma, um método para quantificar esses atributos é construir variáveis artificiais que assumam valores de 1 ou 0 , indicando a presença ou ausência de um atributo (respectivamente), que são conhecidas como variáveis binárias ou dummy.

Sendo assim, utilizar-se-á essas variáveis para incrementar os resultados da regressão. Ainda segundo Missio e Jacobi (2007), a introdução de variáveis qualitativas (dummy) torna o modelo de regressão linear uma ferramenta extremamente flexível capaz de lidar com muitos 
problemas encontrados, principalmente em estudos empíricos. Portanto, serão utilizadas as próprias variáveis que compuseram a DMU, como variáveis dummy: Região Norte, Região Nordeste, Região Sudeste, e Região Centro Oeste; os meses de Outubro e Novembro e as Operadoras 1, 2 e 3. As variáveis Região Sul, Operadora 4 e o mês de Dezembro foram escolhidos para serem o diferencial das demais, portanto, não foram incluídas na tabela para o cálculo da regressão.

Missio e Jacobi (2007) explicam que do ponto de vista econômico, as variáveis dicotômicas dummy são introduzidas no modelo para representar adequadamente os efeitos diferenciais produzidos pelo comportamento dos agentes (econômicos) devido, principalmente, a diferentes causas, dentre as quais se destacam as de tipo temporal (estacionárias, etc), de caráter espacial (estado, país, etc), de caráter puramente qualitativo (sexo, etc). Dessa forma, as variáveis relacionadas às regiões do país e às operadoras visam trazer resultados que apontem qual a interferência dos fatores relacionados com determinada região, determinada operadora ou determinado período do ano (clima, infraestrutura, economia, área de cobertura, etc) que podem influenciar indiretamente a eficiência dos serviços prestados.

\section{ANÁLISE E RESULTADOS}

Os resultados serão apresentados conforme as etapas descritas na seção Metodologia.

\section{Etapa 1: Seleção, qualificação e organização dos dados obtidos da Anatel}

Os dados utilizados para alimentarem os cálculos são provenientes dos Relatórios de Qualidade divulgados pela Anatel, com informações do $4^{\circ}$ Trimestre de 2018. Sendo o DEA, todos os indicadores quantitativos utilizados podem ser tratados como inputs ou como outputs, a depender estritamente dos critérios que estão sendo utilizados durante a concepção da modelagem e da coerência entre eles.

Consoante, Paiva Jr (2000) afirma que a escolha das variáveis deve partir de uma lista ampla de todos os fatores quantitativos e qualitativos, controláveis ou não que evidenciem as relações de produção de um conjunto de DMUs. Esses fatores podem ser outputs que medem os resultados e os objetivos atingidos ou os inputs que são fatores internos ou externos ao sistema que influem nos resultados obtidos.

As variáveis selecionadas dos 14 Indicadores de Qualidade e que foram consideradas mais relevantes para entradas (inputs) são os indicadores de Disponibilidade; Taxas de 
Download, Taxas de Upload. Para representar os outputs foram considerados os dados obtidos do Mapa de Distribuição de Estações de Rádio Base (ERBs) e os índices de satisfação dos consumidores obtidos por meio da Pesquisa Anual de Satisfação. É importante esclarecer que outros indicadores foram testados inicialmente para compor as entradas (inputs) e saídas (outputs), mas não demonstraram possuir tanta relevância para a avaliação da eficiência quanto os selecionados, visto que muitos indicadores trazem avaliações somente por município, como o mapa de cobertura de sinal $2 \mathrm{G}, 3 \mathrm{G}$ e $4 \mathrm{G}$, ou a quantidade de interrupções.

De acordo com Guerreiro (2007), para avaliar a eficiência, as Unidades Tomadoras de Decisão (DMU) devem realizar tarefas similares, de modo que a comparação entre elas faça sentido. Consoante, as DMUs - Unidades de Tomada de Decisão - são uma combinação entre as 27 Unidades da Federação (UF), as Operadoras analisadas, assim denominadas Operadora 1, Operadora 2, Operadora 3 e Operadora 4, sendo as quatro principais operadoras de telefonia móvel do país; e o período analisado - $4^{\circ}$ Trimestre de 2018 , compreendendo os meses de Outubro, Novembro e Dezembro, resultando em uma quantidade de 324 DMUs (27 UF x 4 Operadoras x 3 meses).

Ainda referente às DMUs, Golany \& Roll (1989) ressaltam a importância e o cuidado em determinar o tamanho da amostra antes da definição das variáveis. Uma grande quantidade de DMUs pode diminuir a homogeneidade dentro do conjunto analisado, aumentando a possibilidade de os resultados serem afetados por fatores que foram desconsiderados pelo modelo. Por outro lado, se o tamanho da amostra for menor que a quantidade de inputs e outputs, a análise pode resultar em todas as DMU's serem eficientes. Por isso, alguns autores recomendam que o número de unidades tomadoras de decisão (DMU) deve ser no mínimo duas vezes o número de inputs e outputs considerados.

Sendo assim, foram gerados 4 (quatro) arquivos .csv denominados Operadora 1, Operadora 2, Operadora 3 e Operadora 4 com os dados dos meses de Outubro, Novembro e Dezembro de 2018 para as 3 (três) variáveis de input - Disponibilidade, Taxas de Download e Taxas de Upload - e as 2 (duas) variáveis de output - Distribuição de Estações de Rádio Base (ERBs) e Pesquisa de Satisfação dos Consumidores Ano 2018. As variáveis utilizadas como input e output para o cálculo do DEA são melhor detalhadas no quadro abaixo: 


\section{Tabela 1}

Variáveis utilizadas como input e output

\begin{tabular}{|c|c|c|c|c|}
\hline $\begin{array}{l}\text { VÁRIAVEIS } \\
\text { INPUT }\end{array}$ & DEFINIÇÃO & DESCRIÇÃO & META EM VIGOR & APLICABILIDAD \\
\hline Indicador de Disponibilidade & $\begin{array}{lr}\text { Percentual de tempo } \\
\text { em que o serviço está } \\
\text { em operação, à } \\
\text { disposição r dos } \\
\text { usuários r numa } \\
\text { determinada área de } \\
\text { abrangência em um } \\
\text { determinado período } \\
\text { de tempo. }\end{array}$ & $\begin{array}{l}\text { Mede o tempo em que a rede } \\
\text { da prestadora opera sem } \\
\text { interrupção ou degradação do } \\
\text { serviço. Representa o } \\
\text { percentual de medições } \\
\text { realizadas em que a } \\
\text { disponibilidade da rede foi de } \\
\text { no mínimo } 99 \% \text {, das } 10 \mathrm{~h} \text { - } \\
22 \mathrm{~h}\end{array}$ & $\geq 95 \%$ & Unidade Federativa \\
\hline Indicador de Taxa de Download & $\begin{array}{l}\text { a média da velocidade } \\
\text { contratada ao longo do } \\
\text { mês }\end{array}$ & $\begin{array}{l}\text { Representa a média de todas } \\
\text { as medições realizadas na } \\
\text { rede da prestadora. Deve } \\
\text { atingir no mínimo o } \\
\text { percentual descrito à direita } \\
\text { da velocidade contratada nas } \\
\text { medições realizadas, das } 10 \mathrm{~h} \\
\text { - } 22 \mathrm{~h}\end{array}$ & $\geq 80 \%$ & Unidade Federativa \\
\hline Indicador de Taxa de Upload & $\begin{array}{l}\text { a média da velocidade } \\
\text { contratada ao longo do } \\
\text { mês }\end{array}$ & $\begin{array}{l}\text { Representa a média de todas } \\
\text { as medições realizadas na } \\
\text { rede da prestadora. Deve } \\
\text { atingir no mínimo o } \\
\text { percentual descrito à direita } \\
\text { da velocidade contratada nas } \\
\text { medições realizadas, das } 10 \mathrm{~h} \\
\text { - } 22 \mathrm{~h}\end{array}$ & $\geq 80 \%$ & Unidade Federativa \\
\hline \multicolumn{5}{|l|}{ OUTPUT } \\
\hline Distribuição de Estações de Rádio Base (ERBs) & $\begin{array}{l}\text { A relação da Anatel } \\
\text { inclui todas as ERBs } \\
\text { com potência superior } \\
\text { a } 250 \mathrm{~mW} \text {, ou seja } \\
\text { micro células e outros } \\
\text { tipos de small cells } \\
\text { com esta potência. }\end{array}$ & $\begin{array}{l}\text { A quantidade de Estações de } \\
\text { Rádio Base distribuidas na } \\
\text { UF está diretamente } \\
\text { relacionada com a entrega do } \\
\text { sinal 2G, 3G e } 4 \mathrm{G} \text { e } \\
\text { consequentemente com o } \\
\text { desempenho - qualidade - do } \\
\text { serviços oferecido pela } \\
\text { operadora. }\end{array}$ & NA & Unidade Federativa \\
\hline Pesquisa Anual de Satisfação & $\begin{array}{l}\text { Estudo quantitativo, } \\
\text { com entrevistas } \\
\text { telefônicas coletadas } \\
\text { entre julho a } \\
\text { novembro de } 2018 \text {. }\end{array}$ & $\begin{array}{l}\text { Reflete as pesquisas } \\
\text { realizadas pela Anatel que } \\
\text { medem simultaneamente a } \\
\text { satisfação e a qualidade } \\
\text { percebida pelos consumidores } \\
\text { dos serviços } \\
\text { telecomunicações. }\end{array}$ & NA & Unidade Federativa \\
\hline
\end{tabular}

Fonte: Elaborada pelos autores (2019)

Etapa 2: Geração dos escores de eficiência e análise das informações geradas

Para a realização do cálculo foi necessário definir:

a) A quantidade de entradas e de saídas. Utilizou-se 3 entradas e 2 saídas, conforme detalhado no quadro acima.

b) O modelo a ser utilizado. Foi escolhido o Modelo CCR, que como já visto na seção 3 trabalha com retornos constantes de escala, ou seja, qualquer variação nos insumos 
(inputs) leva a uma variação proporcional nos produtos (output). A eficiência é definida como a razão entre a soma ponderada dos produtos e a soma ponderada dos insumos. Optou-se pelo modelo com retornos constantes à escala (CCR) por não se presumir a existência de efeitos de escala nos resultados dos indicadores de eficiência da ANATEL.

c) Modelagem/Algoritmo. Optou-se pela modelagem Primal. A modelagem Primal do CCR também é conhecida como Modelo dos Multiplicadores, já que os pesos são as variáveis de decisão. O Modelo de Multiplicadores permite que cada DMU escolha os pesos para cada variável (entrada ou saída) de forma que lhe for mais benevolente, desde que esses pesos aplicados às outras DMUs não gerem uma razão superior a um, ou seja, de forma que maximize o valor de sua eficiência (MELLO et al., 2001). Como consequência, o modelo deve atribuir ponderações maiores para variáveis de maior importância ou ignorar variáveis, atribuindo-lhes pesos nulos.

d) A orientação. Optou-se pela orientação à outputs ou segundo a ótica do produto, visto que pretendemos manter os insumos constantes (inputs) e aumentar os produtos para atingirmos a fronteira de eficiência.

A Tabela 1 do Apêndice A contém a relação das 136 DMU's - de um total de 324 com escores de eficiência 1 ou 100\% de eficiência - e os respectivos pesos das variáveis de input e output do $4^{\circ}$ Trimestre de 2018. É possível observar que a aplicação do DEA gera valores de peso para cada uma das variáveis utilizadas, seja como insumos (inputs) seja como produtos (output), para cada DMU. Os pesos são calculados de maneira a maximizar a eficiência da DMU em análise e de forma que esses pesos quando aplicados às outras DMUs da amostra não gerem eficiências maiores do que 1. Essas variáveis são estimativas para as utilidades dos inputs e outputs da DMU avaliada, ou seja, fornece a relevância de cada uma dessas variáveis para aquela DMU, dando a possibilidade da organização classificar os produtos e os insumos por ordem de importância (Mariano et al., 2006).

Pode ocorrer de serem atribuídos pesos zeros a algum input ou output, o que significa que essa variável foi desconsiderada na avaliação. Como exemplo na DMU Operadora2_AP_Out (ver Tabela 1 do Apêndice A), é possível notar que o input Taxa de Download recebeu o maior valor $(0,0211)$, demonstrando possuir maior importância no resultado da eficiência dessa DMU, enquanto os inputs Disponibilidade e Taxa de Upload receberam peso 0 (zero), sendo assim não foram considerados na avaliação, e o output 
Estações de Rádio Base recebeu peso 0 (zero), enquanto a Pesquisa de Satisfação recebeu peso 0,0167 , possuindo maior relevância dentre todos os outputs.

Abaixo segue Tabela 2 contendo as Operadoras mais eficientes e o mês mais eficiente no período. Para obtenção dos resultados, foram analisadas a quantidade de DMUs com Eficiência 1 e a média de eficiência:

Tabela 2

Operadora Mais Eficiente no Período - $4^{\circ}$ Trimestre 2018

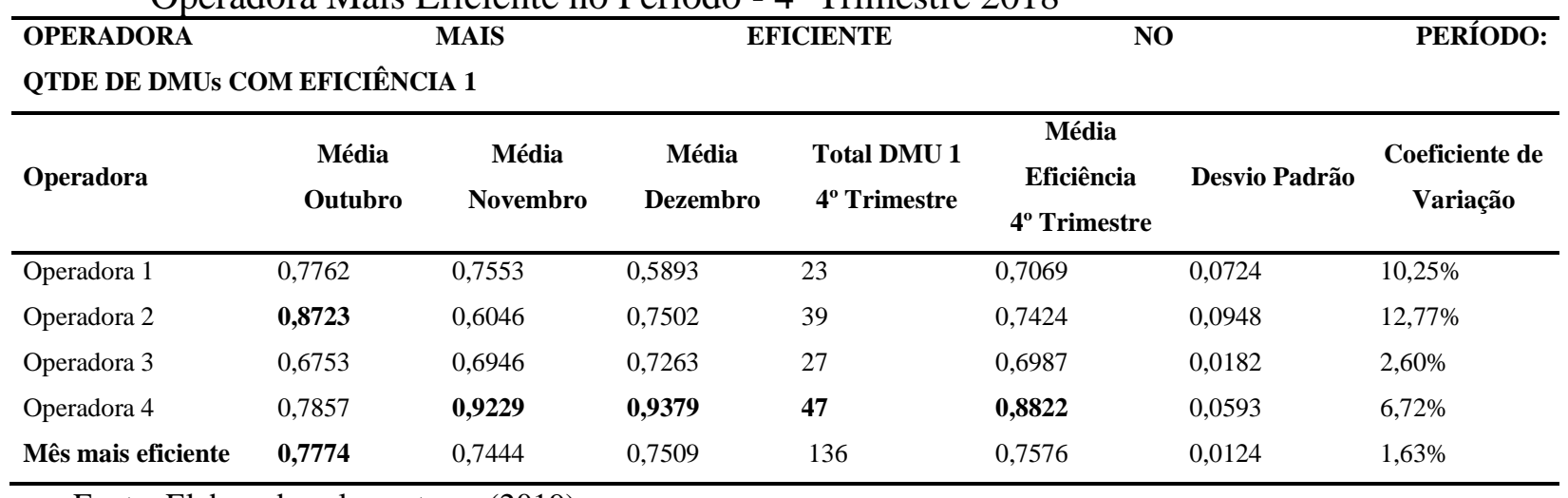

Fonte: Elaborada pelos autores (2019)

Como pode-se notar, a Operadora 4 apresentou maior quantidade de escores de eficiência 1 no período - 47 DMUs com 100\% de eficiência - e apresentou média de eficiência de 0,8822 no trimestre, acima das demais operadoras analisadas, tendo sido a mais eficiente nos meses de Novembro e Dezembro/2018. A Operadora 2 foi a mais eficiente somente no mês de Outubro com média de 0,8723 , mesmo mês em que a Operadora 4 teve a pior média de eficiência - 0,7857, o que levou-a a apresentar um desvio de 0,0593 no período, visto ser uma média bem abaixo das apresentadas nos meses de Novembro e Dezembro 0,9229 e 0,9379 respectivamente. Além disso, Outubro foi o mês com a melhor média de eficiência - 0,7774 de pontuação, contudo, o desvio padrão referente aos meses de Outubro, Novembro e Dezembro é de 0,0124 e o coeficiente de variação é de $1,63 \%$, demonstrando que não houve uma variação muito grande de eficiência entre os meses considerados.

Posteriormente, foi analisada a eficiência por Região Geográfica: 
Tabela 3

Operadoras mais eficientes por região e regiões mais eficientes $-4^{\circ}$ Trimestre de 2018

\begin{tabular}{|c|c|c|c|c|c|c|c|c|c|c|c|}
\hline \multicolumn{12}{|c|}{ OPERADORA MAIS EFICIENTE POR REGIÃO - 4 TRIMESTRE DE 2018} \\
\hline Região & $\begin{array}{l}\text { Média Op } \\
1\end{array}$ & $\begin{array}{l}\text { Média } \\
2\end{array}$ & Op & $\begin{array}{l}\text { Média } \\
\mathbf{3}\end{array}$ & Op & $\begin{array}{l}\text { Média } \\
4\end{array}$ & Op & $\begin{array}{l}\text { Total } \\
\text { DMU } \\
\text { Eficiência } \\
1 \\
\text { por Região }\end{array}$ & $\begin{array}{l}\text { Média } 4^{\circ} \\
\text { Trimestre }\end{array}$ & $\begin{array}{l}\text { Desvio } \\
\text { Padrão }\end{array}$ & $\begin{array}{l}\text { Coeficiente de } \\
\text { Variação }\end{array}$ \\
\hline Norte & 0,7810 & 0,7877 & & 0,6941 & & 0,8524 & & 35 & 0,7788 & 0,0504 & $6,47 \%$ \\
\hline Nordeste & 0,6418 & 0,6540 & & 0,5783 & & $\mathbf{0 , 9 0 3 1}$ & & 37 & 0,6943 & 0,1109 & $15,97 \%$ \\
\hline Sul & 0,6313 & 0,8987 & & 0,6941 & & $\mathbf{0 , 9 9 3 7}$ & & 12 & 0,8045 & 0,1318 & $16,38 \%$ \\
\hline Sudeste & 0,7690 & 0,8571 & & 0,9127 & & 0,8959 & & 36 & $\mathbf{0 , 8 5 8 7}$ & 0,0497 & $5,79 \%$ \\
\hline Centro Oeste & 0,7187 & 0,6298 & & 0,7673 & & 0,7897 & & 16 & 0,7264 & 0,0549 & $7,56 \%$ \\
\hline Operadora mais eficiente & 0,7083 & 0,7655 & & 0,7293 & & $\mathbf{0 , 8 8 7 0}$ & & 136 & & & \\
\hline
\end{tabular}

Fonte: Elaborada pelos autores (2019)

De acordo com os resultados apresentados na Tabela 3, a Operadora 4 apresentou uma média geral de eficiência maior no período analisado - 0,8870 - contra uma média de 0,7655 da Operadora 2; 0,7293 da Operadora 3 e 0,7083 da Operadora 1. Além disso, a Operadora 4 apresentou as melhores médias de eficiência nas regiões - Norte, Nordeste, Sul e Centro Oeste. Sendo que na região Sudeste a Operadora 3 demonstrou ser a melhor no período analisado, ficando a Operadora 4 em segundo posição nessa região.

Em relação as regiões mais eficientes, a região Sudeste ficou com a melhor média do período - 0,8587, com desvio padrão de 0,0497 e coeficiente de variação de 5,79\%, demonstrando que não houve muita variação nas médias de eficiência apresentadas pelas diferentes operadoras avaliadas. A região Sul ficou em segundo lugar com média de 0,8045, entretanto apresentou um desvio padrão de 0,1318 e coeficiente de variação de 16,38\%, demonstrando que houve variações um pouco maiores entre as médias de eficiência.

Por último, é possível verificar as Unidades de Federação mais eficientes e as operadoras mais eficientes em cada uma delas. A Tabela 4, apresenta um mapeamento de quais Unidades de Federação foram responsáveis pelos escores de eficiência recebidos por cada uma das operadoras e onde cada uma delas liderou na pontuação no período analisado:

\section{Tabela 4}

Operadoras Mais Eficientes por UF $-4^{\circ}$ Trimestre 2018

\begin{tabular}{|c|c|c|c|c|c|c|c|c|}
\hline \multicolumn{9}{|c|}{ OPERADORAS MAIS EFICIENTES POR UF } \\
\hline \multicolumn{9}{|c|}{ Quantidade de Escores de Eficiência 1} \\
\hline UF & $\begin{array}{l}\text { Média } \\
\text { Op } 1\end{array}$ & $\begin{array}{l}\text { Média } \\
\text { Op } 2\end{array}$ & $\begin{array}{l}\text { Média } \\
\text { Op } 3\end{array}$ & $\begin{array}{l}\text { Média } \\
\text { Op } 4\end{array}$ & $\begin{array}{l}\text { Total DMU } \\
\text { Eficiência } 1 \\
\text { por UF }\end{array}$ & $\begin{array}{l}\text { Média } \\
\text { Eficiência } \\
\mathbf{4}^{\circ} \text { Trimestre }\end{array}$ & $\begin{array}{l}\text { Desvio } \\
\text { Padrão }\end{array}$ & $\begin{array}{l}\text { Coeficiente de } \\
\text { Variação }\end{array}$ \\
\hline Acre & 0,8960 & 0,5879 & 1,0000 & 1,0000 & 7 & 0,8710 & 0,1510 & $17,34 \%$ \\
\hline Alagoas & 0,6719 & 1,0000 & 0,5955 & 0,9677 & 6 & 0,8088 & 0,1588 & $19,63 \%$ \\
\hline
\end{tabular}




\begin{tabular}{|c|c|c|c|c|c|c|c|c|}
\hline Amapá & 0,7748 & 1,0000 & 0,7791 & 0,7120 & 5 & 0,8165 & 0,0977 & $11,97 \%$ \\
\hline Amazonas & 0,8840 & 1,0000 & 0,4878 & 0,7531 & 5 & 0,7812 & 0,1705 & $21,82 \%$ \\
\hline Bahia & 0,8928 & 0,3847 & 0,4758 & 0,9801 & 4 & 0,6834 & 0,2299 & $33,64 \%$ \\
\hline Ceará & 0,5396 & 0,6815 & 0,7054 & 1,0000 & 7 & 0,7316 & 0,1497 & $20,47 \%$ \\
\hline Distrito Federal & 0,9756 & 1,0000 & 0,7061 & 1,0000 & 10 & 0,9204 & 0,1110 & $12,06 \%$ \\
\hline Espírito Santo & 0,7543 & 0,8358 & 0,8913 & 0,8419 & 5 & 0,8308 & 0,0439 & $5,29 \%$ \\
\hline Goiás & 0,7341 & 0,7042 & 0,8420 & 0,8056 & 3 & 0,7715 & 0,0491 & $6,37 \%$ \\
\hline Maranhão & 1,0000 & 0,6156 & 0,6573 & 0,4433 & 5 & 0,6791 & 0,1806 & $26,60 \%$ \\
\hline Minas Gerais & 0,5361 & 0,5925 & 0,7680 & 0,8099 & 6 & 0,6766 & 0,1029 & $15,20 \%$ \\
\hline Mato Grosso do Sul & 0,7302 & 0,6539 & 0,6538 & 0,7309 & 3 & 0,6922 & 0,0343 & $4,96 \%$ \\
\hline Mato Grosso & 0,4348 & 0,1612 & 0,8673 & 0,6223 & $\mathbf{0}$ & 0,5214 & 0,2311 & $44,33 \%$ \\
\hline Pará & 0,8976 & 0,3398 & 0,9601 & 0,7052 & 4 & 0,7257 & 0,2162 & $29,80 \%$ \\
\hline Paraíba & 0,6453 & 0,4127 & 0,3343 & 0,9497 & 2 & 0,5855 & 0,2141 & $36,56 \%$ \\
\hline Pernambuco & 0,4131 & 0,6983 & 0,4763 & 1,0000 & 4 & 0,6469 & 0,2055 & $31,76 \%$ \\
\hline Piaui & 0,3870 & 0,5999 & 0,6167 & 0,9886 & 3 & 0,6480 & 0,1936 & $29,88 \%$ \\
\hline Paraná & 0,5801 & 0,9713 & 0,6362 & 1,0000 & 4 & 0,7969 & 0,1700 & $21,33 \%$ \\
\hline Rio de Janeiro & 0,7855 & 1,0000 & 0,9913 & 0,9317 & 9 & 0,9271 & 0,0768 & $8,29 \%$ \\
\hline Rio Grande do Norte & 0,3983 & 0,5369 & 0,3634 & 0,8729 & 1 & 0,5429 & 0,1800 & $33,16 \%$ \\
\hline Rondônia & 0,6972 & 0,5860 & 0,7063 & 0,9757 & 2 & 0,7413 & 0,1283 & $17,30 \%$ \\
\hline Roraima & 0,8101 & 1,0000 & 0,7695 & 0,9999 & 8 & 0,8949 & 0,0949 & $10,60 \%$ \\
\hline Rio Grande do Sul & 0,6394 & 1,0000 & 0,4462 & 0,9951 & 5 & 0,7702 & 0,2123 & $27,57 \%$ \\
\hline Santa Catarina & 0,6745 & 0,7248 & 1,0000 & 0,9861 & 7 & 0,8463 & 0,1322 & $15,63 \%$ \\
\hline São Paulo & 1,0000 & 1,0000 & 1,0000 & 1,0000 & 12 & 1,0000 & 0,0000 & $0,00 \%$ \\
\hline Sergipe & 0,8279 & 0,9566 & 0,9800 & 0,9259 & 5 & 0,9226 & 0,0518 & $5,62 \%$ \\
\hline Tocantins & 0,5070 & 1,0000 & 0,1559 & 0,8211 & 4 & 0,6210 & 0,2874 & $46,28 \%$ \\
\hline Operadora mais eficiente & 0,7069 & 0,7424 & 0,6987 & 0,8822 & 136 & & & \\
\hline
\end{tabular}

Fonte: Elaborada pelos autores (2019)

Analisando a eficiência por UF, o estado do Mato Grosso não apresentou nenhum escore de eficiência 1, em contrapartida o estado de São Paulo, o Distrito Federal e o estado do Rio de Janeiro apresentaram a maior quantidade de escores de eficiência 100\% - 12, 10 e 9, respectivamente. Considerando as médias, o estado de São Paulo apresentou a melhor média de eficiência - 1,0000 (100\%), sendo que todas as operadoras analisadas - Operadora 1, Operadora 2, Operadora 3 e Operadora 4 tiveram média 1,0000 (100\%) de eficiência nessa Unidade de Federação. Seguido pelos estados do Rio de Janeiro, Sergipe e pelo Distrito Federal com médias de eficiência de 0,9271, 09226 e 0,9204 nessa ordem, demonstrando que os serviços de Internet móvel operaram com maior eficiência nesses estados no período.

Do ponto de vista de operadora mais eficiente por UF, a Operadora 4 manteve a liderança como a melhor operadora no período avaliado, apresentando a média geral de 0,8822 entre todas as Unidades de Federação avaliadas - números apresentados anteriormente na Tabela 2, e obtendo as melhores médias em 12 Unidades de Federação e o Distrito Federal. Enquanto que a Operadora 2 aparece em segundo lugar, com as melhores médias de eficiência 
em 8 Unidades de Federação e o Distrito Federal, e a Operadora 1 em último lugar, obtendo as melhores médias apenas em 2 Unidades de Federação - São Paulo e Maranhão.

\section{Etapa 3: Cálculo da regressão considerando fatores indiretos - variáveis independentes - que podem influenciar nos escores de eficiência}

A aplicação da regressão neste estudo tem o objetivo de identificar os fatores determinantes da eficiência das operadoras no período analisado. Partindo da análise acima, foram consideradas as eficiências geradas pela aplicação DEA para o cálculo da regressão Tobit. Além disso, foi considerado, conforme explicado anteriormente, outros fatores que podem influenciar indiretamente nos índices de eficiência das operadoras. Sendo assim, a partir deste ponto, tem-se que:

Variável dependente (Y): É constituída pelo escore de eficiência gerado através do DEA. Dessa forma, cada DMU tem um coeficiente positivo que varia de 0 a 1 , calculado através do modelo CCR com orientação para o produto (output).

Variáveis independentes (Xi): Sob esse aspecto, busca-se identificar a influência dos fatores indiretos: IDH; Densidade demográfica (dados do IBGE de Julho de 2018); Produto Interno Bruto (PIB-UF), com dados do IBGE de 2016. Essas variáveis foram coletadas por UF e escolhidas por serem informações que podem afetar indiretamente a qualidade dos serviços ofertados.

Ademais, também serão utilizadas as próprias variáveis que compuseram a DMU, como variáveis binárias ou variáveis dummy: Região Norte, Região Nordeste, Região Sudeste, e Região Centro Oeste; os meses de Outubro e Novembro e as Operadoras 1, 2 e 3. As variáveis Região Sul, Operadora 4 e Dezembro foram escolhidas para serem complementares em combinação linear, portanto, não foram incluídas na tabela. É preciso lembrar que as variáveis dummy são frequentemente chamadas de variáveis binárias, uma vez que assumem apenas um de dois valores - em geral 0 ou 1 - para indicar a ausência ou presença de determinada característica, portanto, somente foi necessário definir qual evento deveria receber o valor 0 (zero) e qual deveria receber o valor 1 (um).

A variável IDH por UF foi utilizada como uma referência para o bem-estar social. Ou seja, espera-se que quanto maior o IDH apresentado pela Unidade de Federação, maior seja o 
índice de eficiência dos serviços prestados pelas operadoras. Isso significa que se espera que o bem-estar social esteja indiretamente relacionado com a maior qualidade dos serviços ofertados naquela região. Assim como a relação entre a densidade demográfica e o PIB-UF pode afetar indiretamente os investimentos em instalações de novas Estações de Rádio Base (ERBs), bem como de novas tecnologias, devido ao aumento da demanda. Desta forma, espera-se ampliar a área de cobertura e melhorar a eficiência dos serviços prestados.

As variáveis relacionadas às regiões do país e às operadoras visam trazer resultados que apontem qual a interferência dos fatores relacionados com determinada região ou determinada operadora (gestão, clima, infraestrutura, economia, área de cobertura, etc) que influenciam indiretamente a eficiência dos serviços prestados.

Quanto aos testes de Normalidade do Modelo, o teste Qui-quadrado mostrou que os resíduos seguem uma distribuição normal, conforme os resultados com $\chi^{2}=20,1647$ e $p$-value de 4,1811E-5. Sendo assim, o modelo da regressão é apresentado na seguinte equação:

$\mathrm{DEA}=\alpha+\beta 1 \mathrm{X} 1+\beta 2 \mathrm{X} 2+\beta 3 \mathrm{X} 3+\beta 4 \mathrm{X} 4+\beta 5 \mathrm{X} 5+\beta 6 \mathrm{X} 6+\beta 7 \mathrm{X} 7+\beta 8 \mathrm{X} 8+\beta 9 \mathrm{X9}+\beta 10 \mathrm{X10}+\beta 11 \mathrm{X} 11+\beta 12 \mathrm{X} 12+\varepsilon$

Onde: $\boldsymbol{\alpha}$ é a constante da função; $\boldsymbol{\beta 1}, \boldsymbol{\beta 2}, \boldsymbol{\beta 3}, \ldots, \boldsymbol{\beta} 12$ que são os coeficientes estimados da regressão; $\boldsymbol{\varepsilon}$ é o fator de erro da regressão e X1; X2; X3; X4, ..; X12 são as variáveis independentes do modelo definidas a seguir:

X1 - Índice de Desenvolvimento Humano por UF (IDH-UF);

X2 - Densidade Demográfica por UF;

X3 - Produto Interno Bruto (PIB-UF);

X4, X5, X6 e X7 - Regiões Norte, Nordeste, Sudeste e Centro Oeste;

X8, X9 e X10 - Operadora1, Operadora 2 e Operadora 3;

X11 e X12 - Os meses de Outubro e Novembro respectivamente.

A Tabela 5 mostra os resultados obtidos pelo modelo de regressão Tobit, com 12 variáveis independentes, sendo 9 dessas, variáveis dummies:

Tabela 5

Resultados do modelo de Regressão Tobit (sig: significância, sendo *Significância a 10\%; **Significância a 5\%, ***Significância a 1\%)

\begin{tabular}{llllll}
\hline \multicolumn{2}{l}{ Resultados Regressão TOBIT } & & & \\
\hline Variável & Coeficiente & Erro padrão & z & p-valor & significância \\
\hline Constante & 0,0587725 & 0,401043 & 0,1465 & 0,8835 & \\
\hline
\end{tabular}




\begin{tabular}{llllll}
\hline PIB & 0,003389 & 0,00551155 & 0,6149 & 0,5386 & \\
IDH & 1,20526 & 0,543169 & $2,22 \mathrm{E}+00$ & 0,0265 & $* *$ \\
DensDemo & $-9,32432 \mathrm{e}-010$ & $4,28 \mathrm{E}-09$ & $-0,2179$ & 0,8275 & \\
Norte & 0,0955442 & 0,0924485 & 1,033 & 0,3014 & \\
Nordeste & 0,047145 & 0,0944338 & 0,4992 & 0,6176 & \\
Centro Oeste & $-0,0956402$ & 0,0729089 & $-1,312$ & 0,1896 & \\
Sudeste & 0,0542529 & 0,0724964 & 0,7484 & 0,4542 & \\
Operadora 1 & $-0,175241$ & 0,0446712 & $-3,923$ & 0,0000875 & $* * *$ \\
Operadora 2 & $-0,139812$ & 0,0446712 & $-3,130$ & 0,0017 & $* * *$ \\
Operadora 3 & $-0,183447$ & $4,47 \mathrm{E}-02$ & $-4,107$ & 0,0000402 & $* * *$ \\
Out & 0,0265102 & 0,0386864 & 0,6853 & 0,4932 & \\
Nov & $-0,00654259$ & 0,0386864 & $-0,1691$ & 0,8657 & \\
\hline
\end{tabular}

Fonte: Elaborada pelos autores (2019)

$\mathrm{O}$ p-valor das estatísticas $\mathrm{Z}$ das variáveis do modelo de regressão Tobit apresentou significâncias somente no IDH (significância a 5\%), e na variável dummy das Operadora 1, Operadora 2 e Operadora 3 (significância a 1\%). Ademais, as variáveis Densidade Demográfica, juntamente com a dummy da Região Centro Oeste e do mês de Novembro, não se mostraram relevantes, o que sugere que para o modelo testado, baseado nos resultados acima extraídos da regressão Tobit, para o período analisado $-4^{\circ}$ Trimestre de 2018 , esses fatores não são fatores decisivos sobre a eficiência das operadoras.

A Densidade Demográfica apresentou relação negativa com a escala de eficiência calculada, portanto, contrariando o esperado, não houve resultados conclusivos a respeito da relação entre densidade demográfica e eficiência na prestação de serviços de Internet Móvel. Em relação às variáveis PIB-UF e IDH, ambas apresentaram relação positiva com a eficiência. Muito embora a variável PIB-UF não foi significativa, pode-se concluir que com um Produto Interno Bruto maior, melhor será sua infraestrutura de telefonia móvel, pois haverá maior exigência por melhor qualidade de serviço. Além disso, baseado na relação positiva do IDH-UF (significativa), indica que as Unidades da Federação que possuem maior bem-estar social tendem a possuir melhores níveis de qualidade de serviços de Internet Móvel.

Baseado nas informações acima, foi feita a análise dos resíduos tendo como base a comparação com a variável dependente (escore de eficiência) e as variáveis independentes, onde chegamos aos resultados de cada operadora. Abaixo - Figura 4 - segue o resíduo da regressão Tobit com a comparação da eficiência expressa em data points de acordo com os dados obtidos das 26 UF e Distrito Federal: 


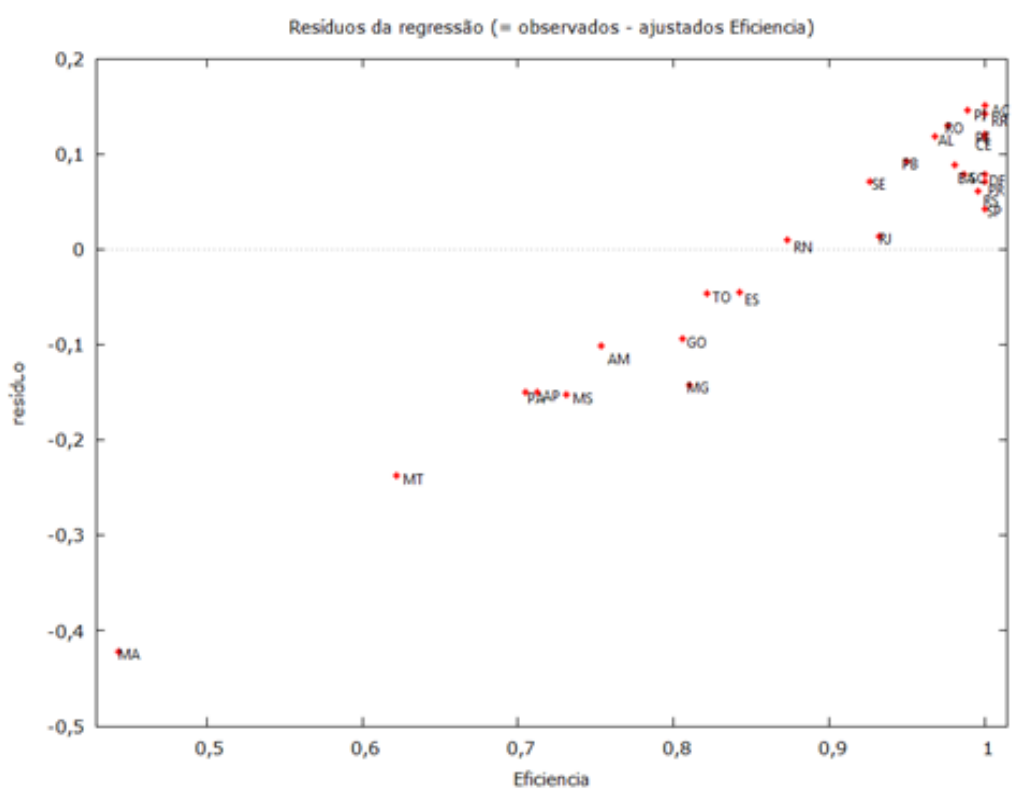

Figura 4 - Resíduos da Regressão

Fonte: Elaborada pelos autores (2019)

\section{CONSIDERAÇÕES FINAIS}

Conhecer os indicadores e metas de qualidade dos serviços de Internet móvel propostos pela Anatel não é suficiente para entender como está a qualidade dos serviços prestados pelas operadoras em todo o território nacional. É necessário entender quais são os fatores que influenciam direta ou indiretamente a eficiência, de modo que o acompanhamento e fiscalização não sejam somente meras ferramentas de autuação, mas que principalmente gerem resultados significativos na melhoria da prestação de serviços aos consumidores.

Para tanto, este trabalho teve como objetivo determinar a eficiência das empresas prestadoras de serviços de Internet Móvel no Brasil por meio do cálculo dos escores de eficiência das Unidades Federativas e Distrito Federal para as 4 (quatro) maiores operadoras de telefonia móvel do país, utilizando como ferramenta a Análise Envoltória de Dados (DEA).

A proposta foi construída com as variáveis de inputs e outputs selecionadas, utilizandose o Modelo DEA CCR e orientação por output. Além disso, foi proposto verificar quais os fatores externos que afetam ou influenciam nessa escala de eficiência, sendo assim, foi realizada a regressão e calculada a correlação entre os escores de eficiência por meio do modelo Tobit.

Com a modelagem orientada a outputs ou segundo a ótica do produto, pretende-se manter os insumos constantes (inputs) e aumentar os produtos para atingir a fronteira de 
eficiência. Por esse motivo, utilizam-se como outputs as informações da Distribuição das Estações de Rádio Base (ERBs) e os resultados da Pesquisa Anual de Satisfação, pois ambos são resultados de ações para melhoria do processo de gestão e prestação de serviços.

Os resultados apresentados mostram que foi encontrado um número razoável de DMUs eficientes, 136, em relação ao número total de DMUs, 324, mostrando uma certa homogeneidade nas Unidades e Operadoras. Sob essa ótica, a Operadora 4 mostrou ser a mais eficiente entre todas as operadoras, pois obteve maior quantidade de escores de eficiência relativa e melhor média de eficiência no período analisado.

Da mesma maneira, com menor dispersão, indicando homogeneidade de eficiência em relação as demais, corroborando com as medidas descritivas anteriores, a operadora 4 apresenta, nos resultados da regressão, um estimador significativo e positivo. As demais variáveis, que representam as outras operadoras, são extremamente significativas, mostrando a importância do modelo de gestão de cada operadora na eficiência.

Também foi avaliada a eficiência por região geográfica do Brasil. A Operadora 4 apresentou a melhor média entre todas as operadoras avaliadas, e as melhores médias de eficiência em 4 das 5 regiões. A Operadora 3 liderou somente na Região Norte. E a Região Sudeste ficou em primeiro lugar como região mais eficiente no período analisado.

Por fim, o estado de São Paulo apresentou média de eficiência de 100\%, seguido pelo Rio de Janeiro, Sergipe e o Distrito Federal com médias acima de 90. Analisando a eficiência por UF, a Operadora 4, novamente, manteve a liderança como a melhor operadora no período analisado, apresentando uma média geral de 0,882 entre todos as Unidades de Federação avaliadas, e obtendo as melhores médias em 12 Unidades de Federação e o Distrito Federal. Destaca-se que os seus índices de eficiência foram crescentes neste período.

Enquanto isso a Operadora 2 aparece em segundo lugar, com as melhores médias de eficiência em 8 Unidades de Federação e o Distrito Federal. A Operadora 1 alcançou o último lugar, obtendo as melhores médias apenas em 2 Unidades de Federação - São Paulo e Maranhão. Observa-se, também, que a operadora 1, diferentemente da operadora 4, decresce em eficiência no período avaliado, o que caracteriza deficiência operacional e de gestão comparada às demais operadoras nesses três últimos meses de 2018.

As análises por UF comprovam o IDH (significativa no modelo) como variável forte para o impacto na eficiência, consequentemente como critério na ampliação e investimento de novas unidades. Partindo desse ponto, baseado na relação positiva do IDH-UF, as Unidades 
da Federação que possuem maior bem-estar social e melhor infraestrutura tendem a possuir melhores níveis de qualidade de serviços de Internet Móvel.

Deve-se destacar que não foram encontradas pesquisas anteriores com proposta de utilização do DEA para avaliação de índices de eficiência de serviços de telefonia móvel ou Internet móvel, porém há trabalhos que empregaram tal metodologia para definição de metas de indicadores de qualidade em outras áreas. Assim como nos estudos realizados nessas outras áreas, a aplicação do DEA para geração dos escores de eficiência das operadoras de telefonia móvel analisadas mostrou que se trata de ferramenta promissora para apoio ao monitoramento e fiscalização da Anatel, visto que utiliza diferentes critérios combinados, não somente critérios quantitativos e qualitativos.

Como sugestão para futuros estudos, há a possibilidade de realizar a mesma análise com base em resultados indesejáveis conforme estudo realizado por P. B. Tschaffon e L. A. Meza (2014). Incluindo, por exemplo, a quantidade de reclamações do serviço prestado como output indesejável, pois trata-se de um output que se deseja minimizar. Quando há outputs indesejáveis, torna-se necessário prover um tratamento para as variáveis diferente do apresentado neste artigo.

\section{REFERÊNCIAS}

Amemiya, T. (1984).Tobit models: a survey. Journal of Econometrics, v. 24, p. 3-61.

ANATEL. Resolução n ${ }^{\circ}$ 575, de 28 de outubro de 2011.

ANATEL. Resolução no 717, de 23 de dezembro de 2019.

ANATEL. Relatório de Qualidade de Telefonia Móvel. Disponível em <http://www.anatel.gov.br/dados/controle-de-qualidade/controle-telefonia-móvel>. Acesso em: 12.06.2019.

Barbosa, S. G. Wilhelm, V. E. (2009). Influência dos Fatores Sociais e Econômicos no Desempenho de Escolas Públicas. Diálogos \& Saberes, Mandaguari, v.5, p.93-109

Bittencourt Neto, S. A. P; Monteiro, S. B. S; Souza, J. C. F; Chaim, R. M. (2018). Using Data Envelopment Analysis to Ranking ICMS's Taxpayers. Mathematics and Computer Science. Vol. 3, No. 2, 2018, pp. 54-66.

Branco Junior, Sergio L.R.F.; Lopes, Ana L. A.M.; Vilela, B. A.; Lima, Reginaldo, J. C. (2018). Data Envelopment Analisys - DEA no setor elétrico brasileiro: uma proposta para validação dos resultados. Revista Gestão e Tecnologia, v.18, n.2, p. 139-171, mai. / ago. 2018

BRASIL. Emenda Constitucional no 8, de 15 de agosto de 1995.

BRASIL. Lei $n^{\circ}$ 9.472, de 16 de julho de 1997.

Dias Junior, C.M., Silva, R. S. S., Costa, E.; Souza, G.P, Cunico,. (2019). A influência do composto mercadológico na eficiência de unidades tomadoras de decisão. Brazilian Journal of Development, Curitiba, v. 5, n. 11, p. 27688-27706, nov. 2019.

Färe, R.; Grosskopf, S.; Lovel, C. A. K. (1994). Production frontiers. NY: Cambridge University Press,

Greene, W. H. (1997). Econometrics Analysis. New Jersey: Prentice Hall,

Guerreiro, A. (2007). Análise da Eficiência de empresas de comércio eletrônico usando técnicas da análise envoltória de dados. PUC-Rio. 
Hoff, A. (2006). Second stage DEA: comparison of approaches for modeling the DEA score. European Journal of Operational Research.

Lins, M. E; Lobo, M. S. C; Silva., A. C. M.; Fiszman, R.; Ribeiro, V.J. de P. (2007). O uso da Análise Envoltória de Dados (DEA) para avaliação de hospitais universitários brasileiros. Ciência e saúde coletiva vol.12 no.4 Rio de Janeiro, July/Aug.

Marinho, A. (2003). A avaliação da eficiência técnica nos serviços de saúde dos municípios do estado do Rio de Janeiro. Revista Brasileira de Economia, v. 57, n. 3.

Missio, F.; Jacobi, L, F. (2007). Variáveis dummy: especificações de modelos com parâmetros variáveis. Ciência e Natura Journal, V. 29, N. 1, 2007. Universidade Federal de Santa Maria, RS.

Moraes, G. M.; Lana, F. V. D.; Lobler, M. L. (2020) Análise da Eficiência dos Investimentos em Tecnologia da Informação. Revista Gestão e Tecnologia, v.10, n.1, p. 1-19, jan-jul 2010.

Moreira, N. P.; Cunha, N. R. S.; Ferreira, M. A. M. S.; Ramos, S. F. (2011). Fatores determinantes da eficiência dos programas de pós-graduação acadêmicos em Administração, Contabilidade e Turismo. Avaliação (Campinas) [online]. 2011, vol.16, n.1, pp.201-230. ISSN 1414-4077.

Oliveira, H. L. S; Meza, L. . A; Lima, G. B. A. Quelhas, O. L. G. (2018). Avaliação da eficiência da indústria brasileira em relação à geração de receita e desempenho em programas de gestão de segurança e saúde através do método DEA. Brazilian Journal of Development, Curitiba, v. 4, n. 5 , Edição Especial, p. 2483-2502, ago

Peña, C. R. (2008). Um Modelo de Avaliação da Eficiência da Administração Pública através do Método DEA. Revista de Administração Contemporânea, Curitiba, Paraná, v. 12, n. 1, p. 83-106.

Sales, G. M. A. (2011). Proposta de um Modelo utilizando Análise Envoltória de Dados - DEA na definição das Metas dos Indicadores da Qualidade Comercial das distribuidoras de energia elétrica - DER e FER. Dissertação de Mestrado ao Departamento de Economia da UnB. Brasília.

Silva, H. B. P.; Ribeiro, A. R. S.; Souza, T. R.; Monteiro, S. B. S; Souza, J. C. F. (2016). Risk Analysis and Quantitative Methods for Mobile Broadband Forecasting in Brazil. Latin America Transactions, IEEE (Revista IEEE America Latina), v. 14, n. 11, p. 4462-4467.

Soares de Mello, J. C. C. B.; Leta, F. R.; Fernandes, A. J. S.; Vaz, M. R.; Soares de Mello, M. H. C.; Barbejat, M.E.R.P. (2001). Avaliação qualitativa e quantitativa: uma metodologia de integração. Ensaio: avaliação e políticas públicas em educação, Rio de Janeiro, v. 9, n. 31, p. 237-251

Soares de Mello, J. C. C. B.; Gomes, L. F. A. M.; Gomes, E. G.; Soares de Mello, M. H. C. (2005). Use of ordinal multi-criteria methods in the analysis of the Formula 1 world championship. Cadernos EBAPE.BR, v.3, n.2,

Sousa, M. C. S.; Souza, J. C. F. (2014). Escores Robustos de Eficiência e seus Determinantes: O caso das agências do Banco do Brasil. Pesquisa e Planejamento Econômico, v.44, n.1. abril

Thanassoulis, E. (1993). A comparison of regression analysis and data envelopment analysis as alternative methods for performance assessment. Journal of Operational Research Society, v. 44, n. 11, p. 1129-1144.

Thiollent, M. (2009). Metodologia de Pesquisa-ação. São Paulo: Saraiva.

Tschaffon, P.; Meza, L. A. (2014). Assessing the efficiency of the electric energy distribution using Data Envelopment Analysis with undesirable outputs. Latin America Transactions, IEEE (Revista IEEE America Latina), v. 12, n. 6, p. 1027-1035, 2014. 